\title{
Selección de posibles marcadores para detectar la presencia de aceites minerales en materiales en contacto con alimentos por GC-MS y APGC-MS-Q-TOF
}

\author{
Janira Jaén, Celia Domeño, Chiara Gajotti, Cristina Nerín \\ Departamento de Química Analítica, Grupo Universitario de Investigación Analítica (GUIA) \\ Instituto de Investigación en Ingeniería de Aragón (I3A) \\ Universidad de Zaragoza, Mariano Esquillor s/n, 50018, Zaragoza, Spain. \\ Tel.+34-976762707, e-mail: janira_jan@yahoo.com
}

\section{Resumen}

Esta investigación explora la utilización de determinados marcadores para detectar, identificar y cuantificar los hidrocarburos aromáticos procedentes de aceites minerales en diferentes materiales, empleando Cromatografía de Gases a Presión Atmósferica acoplada a un Cuadrupolo con un Espectometro de Masas de Tiempo de Vuelo (APGC-MS/Q-TOF).

\section{Introducción}

Los aceites minerales (MOH) son una mezcla compleja de compuestos químicos provenientes del petróleo que pueden ser hidrocarburos saturados (MOSH) constituídos por n-alcanos, isoalcanos y cicloalcanos o hidrocarburos aromáticos (MOAH) que incluyen compuestos poliaromáticos simples y alquilados [1].

Los MOSH no son cancerígenos pero suelen acumularse en las células grasas del cuerpo, en los ganglios linfáticos, el bazo y el hígado, los de cadenas largas, en dosis elevadas, pueden dar lugar a tumores. Asimismo, los MOAH muy alquilados pueden producir tumores $\mathrm{y}$ algunos MOAH sencillos, como el naftaleno, son carcinogénicos no genotóxicos [2].

La contaminación de los alimentos con aceites minerales puede provenir del contacto con materiales reciclados utilizados en envase alimentario como papel y cartón, PET reciclado, pero también de tintas de impresión y lubricantes [3].

El análisis por cromatografía de gases (GC) de los $\mathrm{MOH}$ muestra una montaña de picos no resueltos, con componentes no identificados [2].
Actualmente, no existen estándares de aceites minerales ni materiales de referencia para validar los procedimientos analíticos y la mayoría de las investigaciones realizadas en esta área utilizan cromatografía liquida (LC) en línea con GC-FID. Sin embargo, son pocos los laboratorios que cuentan con este tipo de instrumentación, motivo por el cual esta investigación trata de desarrollar una nueva alternativa para el estudio y análisis de la fracción aromática $(\mathrm{MOAH})$ de los aceites minerales.

\section{Parte Experimental}

\subsection{Reactivos}

Los reactivos utilizados han sido hexano, tolueno, metanol, acetona y diclorometano, todos de grado HPLC suministrados por Sigma -Aldrich.

Los estándares empleados como marcadores fueron: 1,2,3-trimetilbenceno; 1,3-dietilbenceno; 4-tertbutiltolueno, ciclohexil-benceno, bifenilo, acenafteno, fluoreno; 2,6-diisopropilnaftaleno (2,6DIPN), antraceno, fenantreno; 4 metildibenzotiofeno (4-MDBT); 4,6dimetildibenzotiofeno (4,6DMDBT); pireno, benz(a)antraceno, criseno, benzo(a)pireno, 2-Metilnaftaleno, 1- Metilnaftaleno, perileno, 1,3,5tri-terc-butilbenceno, benzo(b)fluoranteno y Benzo[b]nafto[2,1-d]tiofeno. Se preparó una disolución de todos ellos en tolueno con una concentración aproximada de $10 \mathrm{mg} / \mathrm{Kg}$ (ppm) para cada uno.

Para el tratamiento de la muestra se utilizó silica gel $40(0.063-0.20 \mathrm{~mm})$ para cromatografía en columna, silica gel con nitrato de plata $(10 \%$ en peso, 230 mesh) y sulfato de sodio anhidro. Para asegurar la homogenización de la sílice activada con el nitrato de plata, se utilizo el agitador, Vibromatic JP Selecta y se mantuvo en agitación 12 horas. 


\subsection{Muestras}

Las muestras con las que se ha trabajado proceden de aceites lubricantes para distintas maquinarias (hidráulicos, de motor, bombas).

El tratamiento de las muestras consistió en la separación de los MOSH y MOAH utilizando una columna de silica con nitrato de plata al $0.34 \%$. La fracción de MOAH se purificó en una columna con $5 \mathrm{~g}$ de silica desactivada al 3\%, con un diámetro de $2.5 \mathrm{~cm}$ y longitud de $10.0 \mathrm{~cm}$.

\subsection{Condiciones GC}

El equipo utilizado para el análisis fue un cromatografo de gases Agilent 7890A con un automuestreador Combi PAL (CTC Analytics, Zwingen, Switzerland) acoplado a un cuadrupolo TOF MS, Xevo G2 QTOF (Waters Corporation, Manchester, UK), operado en modo APGC con polaridad de API positiva, modo analizador de sensibilidad, rango de masa de m/z 50-650.

\section{Resultados y discusión}

La presencia de aceites minerales en la muestra da lugar a una montaña cromatográfica característica (figura 1) que es un indicador del tipo de contaminación a la que han sido expuestos. La poca definición de esta montaña puede dar lugar a falsos positivos y dudas sobre las características del aceite. La selección de marcadores que permitan distinguir los aceites minerales del resto evitará este problema.

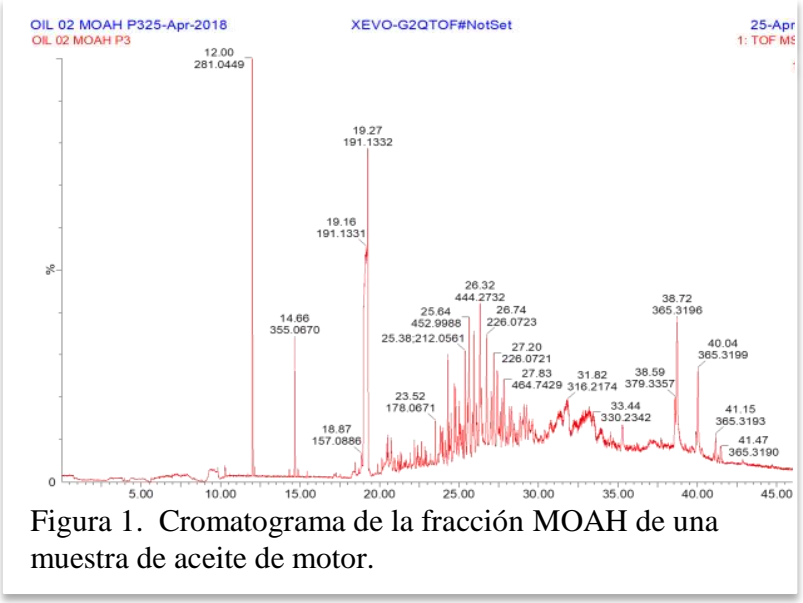

El éxito de la separación de los aceites minerales desde la matriz del lubricante, depende del tipo de disolvente utilizado y de la capacidad de retención de la sílice. Un exceso de disolvente puede arrastrar los lípidos junto con los aceites minerales.

Se ha desestimado el uso de sílice impregnada con ácido sulfúrico como método de eliminación de lípidos, a causa de que algunos de los compuestos aromáticos utilizados como marcadores reaccionan con el ácido sulfúrico y se perdían en el procedimiento.

\section{Conclusiones}

La identificación de algunos de los compuestos seleccionados como marcadores dentro de la montaña cromatográfica de los aceites minerales, confirmará la separación efectiva de los MOAH y el origen petrogénico de la contaminación. El procedimiento podrá aplicarse a diferentes materiales.

\section{REFERENCIAS}

[1]. FISELIER, K., et al. Development of a manual method for the determination of mineral oil in foods and paperboard. Journal of Chromatography A. 2013, 1271, 192- 200.

[2]. EUROPEAN FOOD SAFETY AUTHORITY (EFSA). Scientific opinion on mineral oil hydrocarbons in food. EFSA Journal. 2012, 10(6):2704.

[3]. NESTOLA, M. y SCHMIDT, T. Determination of mineral oil aromatic hydrocarbons in edible oils and fats by online liquid chromatography-gas chromatographyflameionization detection - Evaluation of automated removal strategies forbiogenic olefins. Journal of Chromatography A. 2017, 1505, 69-76.

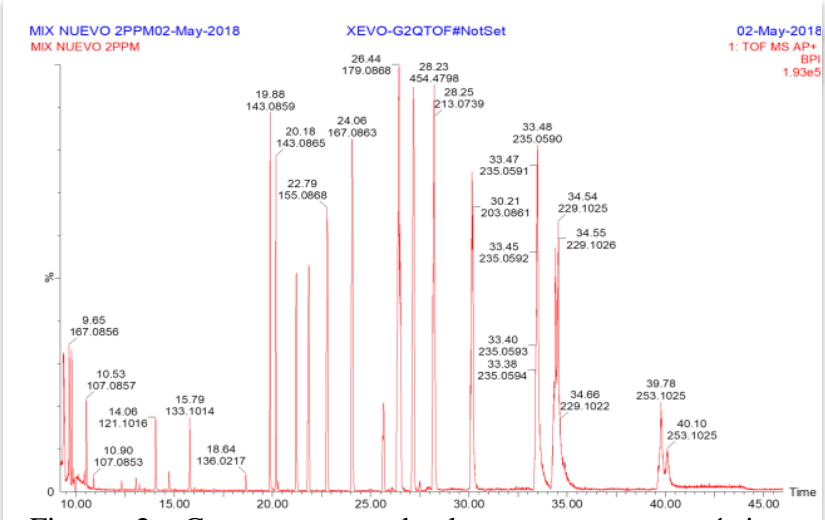

Figura 2. Cromatograma de los compuestos químicos utilizados como marcadores para la fracción MOAH. 